\title{
HIPERATIVIDADE: MITOS E VERDADES NA FORMAÇÃO DE PROFESSORES
}

\author{
Vera Lúcia Messias Fialho Capellini ${ }^{1}$ \\ https://orcid.org/0000-0002-9184-8319 \\ Lys Angélica Grande Lamera² \\ https://orcid.org/0000-0001-8585-5806 \\ Priscila Rocha Machado ${ }^{3}$ \\ https://orcid.org/0000-0001-6700-1030
}

RESUMO: O transtorno de déficit de atenção e hiperatividade (TDAH) atualmente se apresenta como um desafio ao ambiente educacional. A falta de conhecimentos do educador é fonte de erros educacionais, podendo levar a uma mitificação desta patologia. $O$ estudo tem por objetivo avaliar os conhecimentos de alunos de Pedagogia sobre TDAH e analisar disciplinas do curso que o abordavam. Usando questionários estruturados, 201 alunos de Pedagogia foram convidados a participar do estudo. Estes apresentavam questões gerais e possíveis erros de conceitos. Grande parte dos alunos avaliados tinha bom conhecimento sobre TDAH assim como erros conceituais estiveram em uma maior porcentagem entre os alunos de primeiro e segundo anos. Entretanto, nenhuma disciplina do curso de Pedagogia desta instituição discutia especificamente o TDAH. Apesar dos alunos terem conhecimentos adequados sobre TDAH, as disciplinas do curso de Pedagogia não discutiam corretamente este transtorno, pode ser uma explicação pelo qual oTDAH ainda continua como um desafio educacional.

PALAVRAS-CHAVE: Hiperatividade. Formação de Professores. Educação Inclusiva. Mitos.

\footnotetext{
${ }^{1}$ Doutora. Professora e Coordenadora do Curso de Pedagogia.Departamento de Educação da Faculdade de Ciências.Universidade Estadual Paulista Júlio de Mesquita Filho UNESP

Bauru /SP - Brasil.verinha@fc.unesp.br

${ }^{2}$ Doutoranda. Professora Universidade Estadual Paulista Júlio de Mesquita Filho UNESP

Bauru /SP - Brasil.USP - lysbtu@fc.unesp.br

${ }^{3}$ Mestre. Professora Universidade Estadual Paulista Júlio de Mesquita Filho UNESP

Bauru /SP - Brasil.mac_pris@hotmail.com
} 


\section{HYPERACTIVITY: MYTHS AND TRUTHS IN TEACHER EDUCATION}

ABSTRACT: Attention deficit hyperactivity disorder (ADHD) currently presents itself as a challenge to the educational environment. The lack of knowledge of the educator is a source of educational errors, and may lead to a diagnosis of this pathology. The purpose of this study is to evaluate the knowledge of Pedagogy students about ADHD and to analyze the subjects of the course that addressed it. Using structured questionnaires, 201 Pedagogy students were invited to participate in the study. These presented general questions and possible misconceptions. Most of the assessed students had good knowledge about ADHD as conceptual errors were in a higher percentage among first and second year students. However, no discipline in the Pedagogy course of this institution specifically discussed ADHD. Although students have adequate knowledge about ADHD, the subjects of the Pedagogy course did not discuss this disorder correctly, it may be an explanation why ADHD still remains an educational challenge.

KEYWORDS: Hyperactivity. Teacher. Education. Inclusive. Education.Myths.

\section{HIPERACTIVIDAD: MITOS Y VERDADES EN LA FORMACIÓN DE PROFESORES}

RESUMEN: El trastorno por déficit de atención con hiperactividad (TDAH) se presenta actualmente como un desafío para el entorno educativo. La falta de conocimiento del educador es una fuente de errores educativos, que pueden conducir a la mitigación de esta patología. El estudio tiene como objetivo evaluar el conocimiento de los estudiantes de pedagogía sobre el TDAH y analizar los temas del curso que lo abordaron. Mediante cuestionarios estructurados, 201 estudiantes de pedagogía fueron invitados a participar en el estudio. Estos presentaron preguntas generales y posibles errores en los conceptos. La mayoría de los estudiantes evaluados tenían un buen conocimiento sobre el TDAH y los errores conceptuales se encontraban en un porcentaje más alto entre los estudiantes de primer y segundo año. Sin embargo, ninguna disciplina en el curso de Pedagogía en esta institución discutió específicamente sobre el TDAH. Aunque los estudiantes tienen un conocimiento adecuado sobre el TDAH, los sujetos del curso de Pedagogía no discutieron correctamente este trastorno, puede ser una explicación de por qué el TDAH sigue siendo un desafío educativo.

PALABRAS CLAVE: Hiperactividad. Formación de profesores. Educación inclusiva. Mitos. 


\section{INTRODUÇÃO}

O ambiente escolar propicia a troca de experiências culturais, envolvendo um número expressivo de estudantes de faixas etárias variadas, as quais apresentam os mais distintos comportamentos sociais e formas de relacionamento. Dentre tantos alunos, atualmente tem se tornado relativamente comum a identificação daqueles que apresentam características de Transtorno de Déficit de Atenção/Hiperatividade (TDAH).

O TDAH é um transtorno mental de origem neurobiológica, ou seja, não é decorrente de características de personalidade, defeito de caráter, tampouco advindos de fatores ambientais ou educacionais, má educação ou deajustes familiar (ARRUDA, 2008).

Os estudos voltados para o TDAH são muitos e de importância ímpar. Sena e Souza (2013) atestam que "A pesquisa das relações interpessoais em alunos com TDAH é um campo de trabalho desafiador e digno de esforços futuros". Requer o conhecimento da produção científica atual sobre este transtorno nos vários aspectos que o compõem. Dessa forma, não podemos ignorar a necessidade de maior aprofundamento dos profissionais que lidam diretamente com pessoas que apresentam tais características, em particular os professores.

A hiperatividade, ou atividade excessiva, é a manifestação mais comum do aluno com TDAH. É considerado o transtorno mental mais frequente na infância e adolescência (ARRUDA, 2008). Devido ao número expressivo de alunos apontados com características que direcionam para a hiperatividade, 0 presente estudo trata, em específico, deste sintoma dentro do Transtorno de Déficit de Atenção/Hiperatividade, não havendo um aprofundamento maior nos outros também relacionados ao transtorno citado acima como o Déficit de Atenção e a Impulsividade.

\section{Relação professor- aluno}

Uma das relações interpessoais mais importantes na sociedade é a do professor-aluno. Essa convivência precisa ser positiva para que os resultados possam ser significantes a curto e longo prazo para ambos.

O professor que detém informações verdadeiras a respeito do TDAH não se deixará iludir por falsas verdades advindas do senso comum. A quebra dos conceitos pré-concebidos só acontece através do conhecimento. Quando o professor desconhece os reais motivos das ações de seus alunos, pode acabar 
por fazer uma interpretação errônea e não identificar sinais intrínsecos.

Muitos professores não estão se informando adequadamente a respeito do transtorno e suas associações, devido ao pouco acesso a informações comprovadamente científicas e formações inadequadas, realizando assim um trabalho pedagógico improdutivo. Este conjunto de causas e suas consequências tornam o processo de ensino-aprendizagem extremamente complexo, podendo assim afetar drasticamente o desenvolvimento educacional e social do aluno. Corroborando a isto, dificulta-se a convivência do aluno hiperativo seus pares e, principalmente, com o próprio professor. Sabemos ser uma incoerência o desconhecimento por parte dos professores, visto que

Do educador, espera-se também que esteja - segundo a Lei de Diretrizes e Bases (LDB 9.394/96) - em permanente formação para o seu aprimoramento profissional. Atende-se, assim, às novas demandas sociais e até do próprio mercado, que solicita uma sólida formação (SILVA, 2011, p.1).

Em estudo recente, Signor (2013) relata que "a má qualidade do ensino no Brasil está atrelada não somente às práticas pedagógicas pouco eficazes, mas às percepções distorcidas que alguns professores nutrem acerca de sua clientela [...]".

Por meio de pesquisa realizada entre os meses de junho a outubro do ano de 2006 por Gomes et al.(2007) procurou-se apontar o nível de conhecimento acerca do TDAH e os mitos que poderiam constar neste, entre os 2.117 indivíduos pesquisados. Dentre os entrevistados estavam médicos, psicólogos e educadores de todo o Brasil.

Como o público alvo deste presente estudo foram os professores, os números apresentados pela pesquisa referida foram somente os desta população. O resultado apontou que $87 \%$ destes manifestaram conhecimento sobre o TDAH, desses, cerca de $50 \%$ não consideravam o transtorno como uma doença embora $67 \%$ afirmasse conhecer algum aluno com TDAH.

A respeito dos atributos clínicos, $77 \%$ dos educadores acreditavam que o aluno com hiperatividade pode ser tratado apenas com psicoterapia, 59\% acreditavam que muitos alunos apresentavam o diagnóstico de TDAH porque os pais são ausentes e não colocam limites e $52 \%$ defendem que a prática de esportes substitui o tratamento com medicamentos.

Após a apresentação destes dados os autores concluíram que o Brasil demonstrou semelhança com outros países quando se refere à insuficiência de conhecimento acerca do transtorno, tanto na população em geral quanto em 
profissionais envolvidos em seu diagnóstico e tratamento, como os professores, por exemplo, que através da escola são as principais fontes de averiguação e encaminhamento do aluno a órgãos competentes para diagnóstico e tratamento.

Com este desconhecimento ou falta de informação, os professores se apresentam despreparados para reconhecer os primeiros sintomas de um suposto transtorno num aluno dentro de sua sala de aula. Consequentemente, não sabem quais métodos utilizar no processo de ensino-aprendizagem do mesmo. Fator interessante acerca da hiperatividade, apontado por Andrade e Flores-Mendonza (2010), refere-se às associações equivocadas feitas por alguns professores acerca do aluno hiperativo pelo mesmo falar demais, conversar em voz alta consigo mesmo, não acatar ordens imediatas ou se mostrar indisciplinado e desinteressado.

São inúmeros os problemas que podem aparecer na sala de aula devido à falta de conhecimento do professor acerca da hiperatividade, a começar pela intolerância por não ver respeitadas algumas normas pré-estabelecidas para convivência no seu ambiente de trabalho, como por exemplo, o aluno se movimentar sem permissão, brincar em horas inapropriadas, utilizar materiais em momentos inadequados, falar e/ou se intrometer na conversa de outros. Comportamentos como estes podem parecer insignificantes ao primeiro olhar, mas sua repetição extremada pode se tornar um grande empecilho no ambiente escolar.

Cada aluno apresenta sua singularidade, bem com lhe é assegurado (BRASIL, 1990) o direito de expressar suas convicções e serem respeitados em seus limites. Esses apresentam ainda suas próprias necessidades e dificuldades. Relatos de autores afirmam que alunos com hiperatividade têm maior dificuldade para iniciar e manter amizades com os colegas de sala (MESSINA; TIEDEMANN, 2010).

Um apontamento descrito na literatura por Kelly (2001) traduz um significante alarde decorrente a toda essa situação vivida pelos alunos com TDAH. Evidências indicam que tais alunos tendem a estarem presentes nas redes sociais mais degradadas e a se unir umas às outras; chamar a atenção de seus pares na sala de aula por seus comportamentos que fogem ao padrão e normas estabelecidos, aumentando assim a probabilidade de comportamento disruptivo.

É fundamental a intervenção do professor para que o aluno possa desenvolver uma aprendizagem eficaz, ainda mais quando este possui dificuldade de controle de comportamento. Neste momento o professor torna-se não só multiplicador de cultura e aprendizado, mas também um interlocutor 
entre pais e médicos na busca da resolução e entendimento do problema daquele aluno hiperativo.

\begin{abstract}
Os professores declaram com frequência que as crianças com problemas de atenção e comportamento conseguem completar melhor seus trabalhos se interagirem individualmente com um "supervisor" (por exemplo, professor, auxiliar, colega (BARKLEY, 1998).
\end{abstract}

O saber lidar com o aluno hiperativo é essencial, conhecer suas limitações quanto ao seguimento de regras e seus interesses denota a preocupação do professor em realizar com sucesso suas funções de educador. Buscar uma melhor comunicação com o aluno hiperativo ao invés de sempre repreendê-lo transmitirá ao mesmo tempo confiança e interesse.

Em meio às inúmeras dificuldades a serem superadas que se mostram atreladas ao TDAH e ao déficit de informações e articulações por parte do interlocutor da aprendizagem, no caso o professor, constata-se um limiar de conflitos gerados por mistificações alicerçados no transtorno para esconder reais lacunas educacionais.

Os mitos se criam no desconhecido, ao se deixar levar pelo senso comum. Inclusão Escolar não é receber o aluno na sala de aula e esperar que o mesmo se adapte.

O respeito à diversidade deve ser preponderante nas ações do professor e de toda a equipe escolar. "Falar em diversidade é falar de oportunidade, flexibilidade, adaptações e respeito às limitações, dificuldades e necessidades especiais do outro" (FERREIRA, 2007, p.47). Os motivos de se explicar e entender o porquê da classificação de mito para todos estes quesitos acima citados se faz necessário. Há tempos a literatura tenta explicar por muitas variáveis as causas da hiperatividade.

Não há lugar para especulações sem fundamentos ao lidar com as dificuldades de aprendizagem dos alunos, tampouco rotular todos aqueles que apresentam dificuldades de concentração ou de interesse pelos conteúdos trabalhados como hiperativos.

O que pode fortalecer ainda mais a concepção errada do professor, tornando mitificado um conceito ambíguo ao transtorno é o fato da Hiperatividade apresentar maior incidência em pessoas do sexo masculino, os quais já carregam consigo o estigma de serem mais indisciplinados que os do sexo oposto: "No que concerne às diferenças individuais de gênero, pode se concluir, com segurança, que os indivíduos do sexo masculino apresentam médias 
definitivamente mais altas e possuem mais chance de apresentar o transtorno" (ANDRADE E FLORES-MENDOZA, 2010, p.22).

O professor do aluno hiperativo deve manter a flexibilidade pessoal quanto às mudanças em seus métodos de ensino para que possa atender as necessidades constantes do mesmo, refletindo sua práxis pedagógica e procurando inovar o ambiente educacional na busca de tornar o processo de ensino-aprendizagem mais concreto e equilibrado a todos os seus alunos, principalmente aqueles que mais precisarem de seu amparo educacional, sem colocar grandes expectativas quanto às mudanças necessárias no sistema educacional brasileiro, pois o risco de cair no senso comum será grande e não verá modificações concretas nas próprias ações diárias.

\section{Mitos e dificuldades}

Alunos com hiperatividade geralmente demonstram fraca conquista acadêmica. Dentro da sala de aula, estes exibem taxas significativamente mais baixas de comportamentos tidos como adequados relacionado à tarefa durante períodos de instrução e trabalho, diferente dos apresentados pelos demais colegas (DUPAUL; STONER, 2007).

A realidade se apresenta de modo que todos os pais, profissionais e o próprio aluno buscam respostas para os comportamentos diferenciados deste se comparado aos seus pares. "Tanto os pais quanto os professores e os profissionais de saúde, procuram por explicações e maneiras de lidar com os desafios representados pelos comportamentos infantis considerados anormais" (BRZOZOWSKI; CAPONI, 2010, p.5). As dificuldades recorrentes encontradas nestes alunos aumentam o risco de fracasso escolar, sendo estas muitas vezes encaminhadas a serviços de Educação Especial.

Em um apontamento feito por Omote (2004, p.289), chama a atenção o fato de, tendo o aluno diagnóstico de qualquer necessidade especial de aprendizagem, o meio ao qual está inserido acredita que o mesmo deva agir de acordo com suas limitações, não aceitando que este se destaque.

Os mitos levantados acerca da hiperatividade e mantidos por alguns professores podem causar traumas irreversíveis na vida do aluno hiperativo, de seus pares e de seus familiares. Visto que o primeiro passará a acreditar que não é aceito devido a seu mau comportamento e inaptidões, o segundo por não querer associações com indivíduo que foge às regras de disciplina pré-impostas pelo professor e o terceiro pelo sentimento de fracasso.

O reforço é extremamente significante para os alunos com hiperati- 
vidade para que estes possam apresentar um desempenho semelhante ao de seus colegas desde que este seja relativamente imediato e frequente (PFIFFNER \& BARKLEY, 1998).Tarefas claras, curtas e explicadas passo-a-passo também são importantes, tal qual um atendimento individualizado do professor para com seu aluno com hiperatividade. Atividades físicas junto aos conteúdos, organização e planejamento do tempo são de grande utilidade para propiciar ao aluno uma aprendizagem mais eficaz.

Outra grande lacuna deixada pela trama educacional mal organizada e ineficiente é o processo avaliativo. O referido processo deve buscar compreender não apenas o aluno, mas seu contexto educacional, no qual se desenvolve seu processo de ensino-aprendizagem e sua evolução frente a objetivos pré-determinados. Esta forma de avaliação procura valorizar os aspectos diários do aluno e não seu processo normativo diferentemente do que se percebe em muitas escolas brasileiras.

No conceito de Santos (2002, p.448),

[...] importa que sejam criadas as oportunidades de ensino e de aprendizagem aos discentes com deficiência, de modo a ampliar a sua participação no processo educativo e científico, afastando-o de qualquer barreira que impeça o desenvolvimento do conhecimento e a sua formação.

Mannuzza e Klein (2000) justificam o investimento no diagnóstico e o manejo precoce do problema devido às repercussões no mau desempenho escolar dos alunos com TDAH, seu sofrimento pessoal e familiar e sua influência na vida adulta o que corrobora com a primordialidade da busca por informações do professor.

Um fato que a cada dia se faz mais recorrente em escolas é a insistência do professor e de outros profissionais do ambiente escolar junto aos pais para que o aluno com diagnóstico comprovado de hiperatividade esteja sob uso de medicamentos, mitificando que a atenção e concentração deste fossem creditadas ao uso medicamentoso. Não cabe ao professor e a família determinar se o aluno deve ou não ser medicado. Condutas terapêuticas, diagnóstico e profilaxia são de responsabilidade exclusiva de médicos e profissionais de saúde.

Retomando a tríade de Santos \& Vasconcelos (2010), para que uma criança seja considerada de fato hiperativa requer exames e análises de vários profissionais, tais como Psicólogo, Neurologista, Psiquiatra, e os tratamentos variam de acordo com os sintomas apresentados individualmente, mas 
ressaltam que, havendo ou não intervenções psicoterápicas e farmacológicas, "a participação de múltiplos agentes sociais como pais, outros familiares, educadores, profissionais de saúde, além da própria criança" são essenciais para que a mesma se desenvolva.

Êidt e Tuleski (2010, p.140) alertam para o uso desmedido de medicamentos, principalmente em crianças, e ressaltam o real papel do professor ao afirmarem que "a linguagem atua como o principal instrumento psicológico na regulação da conduta na criança, seja no domínio da atenção ou do autocontrole do comportamento". Ainda segundo os autores "Essa regulação não surge espontaneamente na vida cotidiana, mas resulta de um processo educativo intencional, inicialmente na família e depois na escola".

Miranda (2012) afirma que as transformações pelas quais vem passando a comunidade educacional, rompendo com paradigmas estabelecidos para a Educação Especial, e o aumento no número de matrículas de alunos com NEE na Educação Regular, fomentam ações inovadoras que ofertam práticas pedagógicas que atendam cada um deles em suas especificidades, bem como a adequação do ambiente escolar. Ressalta ainda a "importância da atuação do professor e a dinâmica da sala de aula, representadas pela formação docente, pelo trabalho pedagógico e diferentes possibilidades educativas, desenvolvidas no espaço escolar".

\section{Metodologia}

Em meio à realidade em que a hiperatividade se apresenta, devido a inúmeras conjecturas influenciadas por mitos, informações não comprovadas cientificamente, nos deparamos com indagações relacionadas a ela que nos sugerem refletir sobre seu contexto. A busca de uma elucidação consistente dos mitos e verdades envolvidos no ambiente escolar que abrangem o problema acima citado se mostra inerente ao processo educativo do aluno com hiperatividade.

O presente estudo foi validado pelo Comitê de Ética da Universidade Estadual Paulista, campus de Bauru. Hipóteses norteadoras ao transtorno foram elaboradas para darem possíveis diretrizes aos questionamentos a serem levantados. Os futuros professores estão realmente preparados para receber um aluno hiperativo em sala de aula? O conhecimento científico do futuro professor em relação ao Transtorno de Hiperatividade é profícuo? Qual a influência dos mitos sobre o Transtorno de Hiperatividade na ação educativa do futuro professor? 
Pretendeu-se assim elaborar, além de um levantamento teórico a respeito do tema, seu envolvimento com a sala de aula, qual o conhecimento cabível com a literatura científica e quanto os conhecimentos dos professores podem estar voltados para os mitos, ou seja, inverdades sem comprovação científica.

Alunos com hiperatividade necessitam de um acompanhamento com profissionais relacionados à área da saúde mental maior do que aqueles que não o tem. Arruda(2008) define que o TDAH é um transtorno mental crônico, ou seja, se manifesta e evolui ao longo da vida, ao contrário de outras condições agudas cuja duração limita-se a horas ou dias.

Portanto, torna-se inegável a importância do professor conhecer atitudes sintomáticas, pois na maioria das vezes, são eles que irão dar o sinal de alerta para os pais e os ajudarão a ter acesso aos serviços médicos informando-os e orientando-os sobre as dificuldades de seu filho.

Apesar da hiperatividade não ser a principal causa de um aluno apresentar dificuldades de aprendizado, esta pode ser uma condição expoente para que este tipo de situação ocorra. Ser professor exige estudos contínuos nos campos da didática tanto em teoria como na prática.As mudanças socioculturais, tecnológicas e econômicas ocorrem rapidamente, as quais vão além dos conteúdos programáticos escolares. Inúmeros são os fatores que fazem do exercício do magistério uma atividade ímpar.

A formação do professor pode não possuir tempo suficiente para transmitir a estes conceitos de cidadania e respeito com a veracidade necessária para a realização de um trabalho de qualidade. Atualmente, muitos pesquisadores têm apontado a Educação Continuada como um recurso de complementação da formação do professor.

A Formação Continuada tem sido considerada um importante processo para que o professor não se sinta despreparado, nem tampouco desmotivado pelas constantes transformações pelas quais a sociedade vem passando. Silva (2011, p.10) afirma que "a formação contínua é um caminho percorrido por aqueles que sentem necessidade de desenvolvimento profissional, que possa ajudá-los a terem consciência das dificuldades, ressignificá-las e construírem soluções." Muitos cursos de Formação Continuada estão voltados para a Inclusão Escolar, pois acreditam ser este o fator mais urgente pelo qual necessita a educação brasileira.

A formação profissional do professor deve ir além das informações acerca dos conteúdos e metodologias a serem trabalhadas, um dos objetivos primordiais (ao menos assim deveria ser) é despertar o gosto do aprender 
sempre mais, não se limitar à conclusão do curso e agir sempre de maneira engessada.

Objetivando-se conhecer o quanto a literatura corresponde à realidade nos cursos de Formação de Professores relacionando-os ao TDAH, elaborou-se uma pesquisa quali-quantitativa com alunos do 1 은 a 4 o ano do curso de Pedagogia da Universidade Estadual Paulista "Júlio de Mesquita Filho" campus de Bauru.

Como instrumento da coleta de dados, foi elaborado um questionário estruturado relacionado ao Transtorno de Hiperatividade, distribuído aos discentes de Pedagogia, na tentativa de avaliar o nível de conhecimento desses alunos sobre o tema.

Duzentos e um alunos foram submetidos à pesquisa, totalizando 100\% do corpo discente do referido curso. Obteve-se a devolução de cento e dezoito dos duzentos questionários entregues, ou seja, 59\% do público alvo. O único critério de seleção para o participante era que este fosse aluno graduante do curso de Pedagogia da UNESP/Campus de Bauru.

O questionário, bem como as afirmações contidas no instrumento de coleta de dados, foi elaborado de acordo com dois livros referendados pela literatura cientifica pertinente, são eles: Mattos (2005)No mundo da lua: perguntas e respostas sobre transtorno de déficit de atenção com hiperatividade em crianças, adolescentes e adultos e Arruda(2008), Levados da breca, e que servem como base para o conhecimento da hiperatividade no Brasil. Os autores científicos foram escolhidos para que não se misturassem conceitos científicos e populares. Ambos os autores escreveram seus livros baseados em dados de pesquisa comprovados, não se deixando agregar "achismos" e o senso comum.

Durante revisão bibliográfica realizada para a construção desta pesquisa, chegou-se a questões que poderiam explicitar quais eram os "mitos" existentes na opinião de educadores, pesquisadores e da população atual acerca do assunto hiperatividade. Estas questões permearam esta dando possíveis respostas às indagações propostas.

O questionário investigativo trazia apontamentos verdadeiros e "falsos" (sem comprovação científica) no formato que continha três alternativas (concordo, discordo e não sei). Isto permitiu ao respondente assinalar qual deles seria em seu conceito pessoal, o verdadeiro.

Nem todos os alunos estavam presentes na sala no momento da entrega dos questionários, entretanto, a quantidade obtida foi de grande significância para a análise dos possíveis mitos e verdades a respeito do tema hiperatividade nos alunos do curso de Pedagogia, já que os resultados ultra- 
passaram a marca dos $50 \%$ da população.

A análise dos resultados foi verificada através de gráficos que apontaram a porcentagem do valor absoluto das respostas dos alunos nos três quesitos do resultado, que se constituíam em "concordo", "discordo", "não sei" e a totalização destes itens.

De acordo com cada afirmativa foi elaborado um gráfico que indica a porcentagem destes três itens nas respostas dos alunos dos quatro anos de Pedagogia. Ao todo foram 10 afirmativas contendo os três itens e o total. 0 valor absoluto foi obtido a partir do número total dos alunos respondentes e quantos destes alunos responderam "concordo", "discordo" ou "não sei" em cada afirmativa. O resultado foi apontado na forma de percentual.

TABELA 1- Balanço geral dos graduandos em Pedagogia da UNESP/Bauru (continua)

\begin{tabular}{|c|c|c|c|c|c|c|c|c|}
\hline \multirow[b]{2}{*}{ ANOS } & \multicolumn{2}{|c|}{ MATRICULADOS* } & \multicolumn{2}{|c|}{ RESPONDENTES } & \multicolumn{2}{|c|}{$\begin{array}{c}\text { NÃO } \\
\text { AUTORIZARAM } \\
\text { A PARTICIPAÇÃO } \\
\end{array}$} & \multicolumn{2}{|c|}{$\begin{array}{c}\text { ABSTENÇÃO } \\
\text { POR ANO }\end{array}$} \\
\hline & $\begin{array}{c}\text { VALOR } \\
\text { ABSOLUTO }\end{array}$ & $\%$ & $\begin{array}{c}\text { VALOR } \\
\text { ABSOLUTO }\end{array}$ & $\%$ & $\begin{array}{c}\text { VALOR } \\
\text { ABSOLUTO }\end{array}$ & $\%$ & $\begin{array}{c}\text { VALOR } \\
\text { ABSOLUTO }\end{array}$ & $\%$ \\
\hline 1 은 & 56 & 28 & 23 & 20 & 0 & 0 & 23 & 41 \\
\hline 20 & 51 & 25 & 26 & 22 & 0 & 0 & 25 & 51 \\
\hline 3으 & 43 & 21 & 24 & 20 & 0 & 0 & 19 & 56 \\
\hline 49 & 51 & 25 & 45 & 38 & 0 & 0 & 06 & 88 \\
\hline
\end{tabular}

Fonte:LAMERA, 2014.

Este trabalho também subdividiu as disciplinas que poderiam dar ênfase ao TDAH no curso de Pedagogia, em dois eixos. O primeiro eixo elencou as disciplinas do primeiro currículo do curso de Pedagogia da UNESP/Bauru vigorado até o ano de 2006, o qual foi substituído pelo currículo reestruturado.

O acompanhamento teórico é de extrema necessidade para se aprofundar em um tema tão presente nas realidades escolares brasileiras e mundiais. Abordar um tema tão tênue e cheio em detalhes, mitos e inverdades como os problemas de aprendizagem se faz mais que necessária a presença 
de uma bibliografia verdadeira e cientificamente comprovada para embasar os conhecimentos dos futuros pedagogos para que estes possam trabalhar de forma inclusiva, proporcionando aos seus alunos uma aprendizagem sem mitificações da cultura popular.As respostas corretas pela literatura científica eram o eixo da análise investigativa de como os mitos influenciavam os futuros pedagogos. As respostas incorretas também foram averiguadas para se mensurar a quantidade de possíveis mitos na concepção da hiperatividade nos alunos da Pedagogia.

\section{Apresentação e análise dos resultados}

Os educadores, além dos pais/responsáveis, são as pessoas mais presentes no dia-a-dia do aluno com hiperatividade. O convívio diário exige paciência e coragem para vencer grandes desafios. A intervenção do professor deve ser feita de forma a buscar a inclusão de todos os alunos no contexto escolar principalmente se em sua sala de aula estiver um portador de hiperatividade, estimulando a aprendizagem e fortalecendo o ambiente educativo.

O transtorno de hiperatividade está cada vez mais frequente no contexto escolar, tanto pelos inúmeros pré-diagnósticos feitos às crianças que são exclusivamente ativas em excesso, quanto pelas que realmente o possuem.

A falta de informação do professor ativo no processo de aprendizagem do aluno com hiperatividade, pode repercutir e muito no andamento acadêmico deste, podendo até mitificar situações em que o conhecimento científico não se fez presente, por exemplo, criando rotulações de que todas as crianças que apresentarem em sala de aula um comportamento disruptivo são hiperativas, se comportam desta maneira porque querem e não conseguiram aprender.

As mitificações etiológicas também podem persuadir o professor leigo, causando confronto entre a verdade e o incerto, possibilitando a criação de um ambiente hostil e insatisfatório para quem convive com o aluno hiperativo, com seus anseios e com seu comportamento dificultoso e evidentemente para si próprio.

O exercício do Magistério exige amplos conceitos e responsabilidades. O Referencial Curricular Nacional para a Educação Infantil (BRASIL, 1998) explicita o educar, computando a este o favorecimento de situações de aprendizagem sob orientação do professor e que esses, por sua vez, venham auxiliar no "desenvolvimento das capacidades infantis de relação interpessoal, de ser e estar com os outros em uma atitude básica de aceitação, respeito e confiança, e o acesso, pelas crianças, aos conhecimentos mais amplos da 
realidade social e cultural".

Ao dar a possibilidade do aluno graduando em Pedagogia debater a escola inclusiva e adaptações em seu currículo, o curso proporciona ao futuro professor um vasto repertório teórico, mais especificamente a hiperatividade, assunto primado por esta pesquisa, visões de grandes autores sobre o tema e aplicações de modelos de trabalho que aproximem o aluno de um processo educativo, tornando o ambiente escolar mais agradável, passível de grandes realizações, tratando-se de proporcionar uma aprendizagem verídica a todos.

Para tentar averiguar de onde provinham os conhecimentos acerca do TDAH dos alunos de Pedagogia, foi elaborado um levantamento das disciplinas que poderiam vir a abordar o tema em seu conteúdo ministrado em aulas do curso. Havia disciplinas que poderiam ter explanado sobre o tema, todavia em muitas delas o contexto do problema ficava intrínseco nas ementas não chegando a ser pauta para as aulas que viriam a serem dadas aos alunos.

O primeiro ano não dispunha de nenhuma disciplina que pudesse dar embasamento teórico acerca do tema, o que pode vir a justificar muitas das respostas carregadas de dúvidas e incertezas obtidas por este grupo de alunos, já que muitas destas poderiam ter sido frutos de estudos e vivências próprias dos alunos.

As grades curriculares do curso de Pedagogia trazem as disciplinas que tem como objetivo abordar as Necessidades Educativas Especiais. No currículo antigo este tipo de disciplina chamava-se Desenvolvimento Humano III - Necessidades Educativas Especiais. No currículo atual esta aparece com o título de Educação Inclusiva.

A disciplina contida no currículo antigo, ministrada aos alunos concluintes do curso no segundo ano deste, apresentava em sua ementa e em seus objetivos, conhecimentos e teorias que deveriam ser estudados pelos alunos, que abrangiam desde as deficiências físicas e motoras até distúrbios e dificuldades de aprendizagem. Esta disciplina é de extrema relevância para os alunos de Pedagogia, visto a quantidade de problemas relacionados a estes temas que estão cada vez mais presentes em sala de aula.

Os alunos dos anos iniciais como o primeiro, segundo e terceiro ano não puderam contar com o embasamento teórico da disciplina Educação Inclusiva no ato da pesquisa, pois esta somente seria ministrada aos alunos no último semestre do quarto ano.

Os alunos do quarto ano obtiveram altas percentagens em afirmativas que exigiam uma quantidade maior de reflexão sem grandes aprofundamentos teóricos, o que perpetua ainda mais a ideia de que a disciplina mencionada 
acima não conseguiu dar vazão ao conhecimento acerca do TDAH.

Ao se avaliar as respostas dos alunos dos quatro anos do curso, tentou-se apontar o nível de conhecimento destes acerca do TDAH e quantificar a variedade de mitos, conhecimento sem comprovação científica e as verdades baseadas na literatura presentes nestas respostas. Em suma, todas as respostas dadas pelos alunos apresentaram a presença de dúvidas. No entanto o índice de acertos foi satisfatório levando-se em consideração que os três anos iniciais ainda não haviam tido contato com a disciplina de Educação Inclusiva. Por vivências pessoais, leituras superficiais ou conhecimento básico prévio, os alunos apresentaram um conhecimento baseado em verdade, ou seja, de acordo com a literatura científica. Entretanto o número de respostas na alternativa Não Sei foi marcante, identificando ao leitor a existência de inúmeras dúvidas ou o desconhecimento de alguns alunos acerca do transtorno de hiperatividade, tão presente no contexto da aprendizagem infantil atual.

Dentre os muitos mitos presentes no senso comum, o presente estudo elencou alguns mais difundidos entre a população educativa. Foi explorado o TDAH visto ser um tema passageiro, discutido para vender medicamentos e propagar a indústria farmacêutica pertinente a hiperatividade atingindo somente crianças de 3 a 6 anos, toda criança que fala e se comunica excessivamente como portadora de hiperatividade, o TDAH um transtorno de personalidade e denotado de fatores ambientais somente, o TDAH atingindo em sua maioria nas classes sociais menos favorecidas e a criança hiperativa como um possível mau aluno, sempre propensa aos maus rendimentos e péssimo rendimento escolar em toda sua vida acadêmica.

Para tentar fazer o discente que estaria respondendo refletir acerca do que se propusera, foram colocadas alternativas pertinentes a literatura científica como a criação de rótulos por parte de colegas e professores de classe em aluno que apresentam TDAH e a hiperatividade como sintoma do transtorno TDAH.

A afirmativa que apresentou a hiperatividade como "modismo" termo este muito utilizado nas fontes sem aparato científico e a afirmativa que classificava todas as crianças com movimentações corporais excessivas como hiperativas, dois mitos muito difundidos entre a população, identificaram que os alunos dos quatro anos do curso de Pedagogia através de seus índices de respostas não mantiveram seus conhecimentos apoiados nestes tipos de mitos, alcançando uma margem de 60 a $80 \%$ elencados na alternativa Discordo.

Já em outro questionamento, ficou clara a presença de um mito muito propagado por alguns autores, mas que ainda não encontrou respaldo 
e veracidade na literatura científica dada a sua não comprovação. Este mito explana que o TDAH é causado por fatores ambientais e sociais tornando os pais das crianças hiperativas como "protagonistas". Os índices Não Sei e Discordo ficaram equiparados entre os alunos dos quatro anos do curso.

$\mathrm{O}$ instrumento de coleta continha três afirmativas que propunham a reflexão do futuro pedagogo e seu conhecimento prévio a respeito de como seria sua sala de aula caso houvesse um aluno com transtorno de déficit de atenção/hiperatividade. Tais como: se hiperatividade era algo que atingia somente a população infantil de 3 a 6 anos no inicio da fase escolar; se os problemas comportamentais que apareciam com os alunos com TDAH poderiam provocar a criação de rótulos; comportamentos esquivos de amigos e professores e consequentemente a exclusão e se ao deixar a lousa cheia; a classe com muitos cartazes; falar várias informações de uma vez e formar grupos com mais de dez amigos para a execução de trabalhos, seriam formas de auxiliar os alunos com hiperatividade.

As respostas obtidas foram bastante satisfatórias quanto ao ponto de vista reflexivo apesar da forte presença de pontuações na alternativa Não Sei nas turmas iniciais. As totalidades dos índices alcançados foram acima dos $60 \%$ na alternativa. Concordo para a afirmativa que se referia à criação de rotulação e exclusão. Na afirmação que expunha o modo de agir e executar suas funções pedagógicas como professor de um aluno com TDAH, os índices totais mostraram $70 \%$ de apontamentos na alternativa. Discordo, o que é muito emblemático, pois demonstrou uma conscientização favorável ao modo de corresponder pedagogicamente a um aluno hiperativo. O questionamento acerca da faixa etária em que TDAH fica mais evidente na criança demonstrou sérias dúvidas dos alunos, deixando-os na marca de $50 \%$ da totalidade na alternativa Não Sei.

Após a análise dos dados estatísticos, o presente estudo averiguou a existência de disciplinas, nos dois currículos vigentes, que poderiam explanare informar o aluno sobre a existência do TDAH em sala de aula e evidentemente seu impacto no aluno hiperativo e em todos que o cercam bem como auxiliar o mesmo a desenvolver, de acordo com a literatura adequada, formas e adequações pedagógicas para que haja um processo educativo eficaz.

Como segundo objetivo deste estudo, subdividiram-se as disciplinas que poderiam dar ênfase ao TDAH em suas ementas e planos de curso, em dois eixos. As disciplinas do currículo antigo que poderiam ter explicitado em seus conteúdos a hiperatividade foram escolhidas de acordo com suas ementas e seus objetivos assim como as do currículo novo. 
Entre as inúmeras disciplinas do curso de Pedagogia do primeiro currículo verificaram-se as denominadas Educação e Desenvolvimento Humano I, II, III, IV- Bases biofísicas, bases psico - sociais, necessidades educativas especiais e ensino e aprendizagem, Prática de Ensino I e Il e estágio Supervisionado I e II.

Pelas ementas destas disciplinas fez-se notar que a única disciplina que citava o tema distúrbios e dificuldades de aprendizagem era a disciplina Educação e Desenvolvimento Humano III- Necessidades Educativas Especiais, demonstrando que o curso de Pedagogia da Universidade Estadual Paulista "Júlio de Mesquita Filho", admite e objetiva explorar os referidos temas juntamente com seus graduandos. Se todo este conteúdo se faz cumprir não se pode prever e afirmar no presente momento, já que anualmente há mudanças no corpo docente os planos de curso pessoais se modificam cada qual a seu modo. Imagina-se que a presença do tema dentre os muitos abrangidos por esta disciplina já aponta para uma possível futura discussão e aprendizado a respeito deste.

As disciplinas elencadas por emenda, pertencentes ao currículo reestruturado foram escolhidas dentre as que estavam abrangendo os alunos até o $3^{\circ}$ ano, visto que estes foram os alunos respondentes englobados neste currículo, os alunos do $4^{\circ}$ ano pertenciam ao currículo antigo. Foram analisadas as disciplinas de Prática de Ensino: a Didática na Práxis Pedagógica e nos Anos Iniciais do Ensino Fundamental, Avaliação na Aprendizagem e Estágio Supervisionado.

Em nenhuma das ementas destas disciplinas citavam o TDAH ou a hiperatividade. A disciplina Avaliação na Aprendizagem poderia ter abordado a hiperatividade quando se propõem analisar o erro no processo de avaliação do ensino e da aprendizagem, considerando que o aluno com TDAH por sua tendência a distração, inquietude e impulsividade pode apresentar uma aprendizagem abaixo do nível esperado, muitas vezes devido à condição educacional deficitária e sua subestimação nos processos avaliativos.

Em Estágio Supervisionado, os discentes poderiam ter contato com a temática hiperatividade no momento da intervenção prática. O conhecimento das diferentes abordagens didáticas permitirá ao professor adequar-se melhor às necessidades de seu aluno hiperativo, permitindo a este um desenvolvimento eficaz de sua aprendizagem, fazendo com que esta aconteça de modo coerente e delineado conforme suas particularidades.

Ao analisar os dois currículos em que o curso de Pedagogia se fundamenta o antigo e o reestruturado, pode-se perceber que o segundo currículo apresentado aos alunos dos três primeiros anos em vigor, disponibiliza maiores 
suportes de aprendizagem em relação aos processos pela qual esta é norteada, dando possibilidades de ênfase aos transtornos como hiperatividade maiores que o currículo antigo mantido em uso pelos alunos do quarto ano do curso.

\section{Considerações finais}

São inúmeros os motivos pelo qual se pode tentar explicar as causas da desinformação demonstrada pelos alunos ao serem submetidos aos questionários temáticos sobre o Transtorno de déficit de atenção/hiperatividade.

Pode-se perceber que os alunos de Pedagogia souberam identificar a hiperatividade como uma dificuldade real da infância podendo se prolongar para a vida adulta e discerniram o aluno hiperativo do aluno que apresenta dificuldades de aprendizagem sem necessariamente possuir o TDAH.

Este resultado pode sugerir que os alunos do curso poderiam entender as circunstâncias da hiperatividade e dos alunos que a possuem. É evidente que somente estes apontamentos não garantem que os futuros pedagogos estariam realmente preparados para atender todas as necessidades do aluno hiperativo e sua globalidade, mas conheceriam a faixa etária que a hiperatividade atinge e não usufruiriam da unanimidade para equiparar alunos e seus desempenhos escolares.

Os resultados dos questionários registraram que o nível de conhecimento dos alunos da Pedagogia a respeito da hiperatividade era superficial, sem grandes aprofundamentos na literatura pertinente ou meios científicos que proveriam informações verdadeiras sobre o transtorno. De acordo com as proposições contidas no questionário e mais especificamente nas afirmativas que transcreviam o mito como verdades, para serem analisadas pelos futuros pedagogos, os resultados apresentados foram equiparados.

Faz-se por bem explanar que somente mensurar as respostas contidas no questionário não traduz com integralidade que o aluno de Pedagogia de fato construiria um ambiente pedagógico inclusivo ao aluno com hiperatividade, já que este tipo de ambiente se constrói de diferentes formas atendendo as mais variadas necessidades do indivíduo, que seriam muitas para poder se colocar em um questionário de pesquisa, desde um perfil profissional predisposto a aceitar o aluno hiperativo até a sala de aula com aparatos materiais acessíveis.

As proposições não comprovadas cientificamente, os mitos, apareceram nas entrelinhas das respostas, principalmente aquelas que explicitavam o contexto ambiental e social da criança hiperativa, mas sua presença não se perpetuou dentre a maioria dos alunos, o que pode trazer contribuições 
significativas para os alunos destes respondentes.

De acordo com Projeto Político-Pedagógico do curso de Pedagogia, seu eixo articulador entre teoria e prática são as disciplinas Prática de Ensino e Estágio Supervisionado. Estas visam contextualizar e visualizar o processo de formação do educador-docente, portanto seria de extrema relevância a participação e comprometimento do docente destas disciplinas no conhecimento elaborado dos alunos quanto aos problemas educacionais que estes poderão vir a encontrar em sala de aula, principalmente os transtornos e distúrbios inerentes a aprendizagem acadêmico-escolar.

De acordo com os objetivos específicos do curso relatados em seu PPP destacam-se que o curso deve garantir ao aluno concluinte o "domínio dos conteúdos a serem socializados, seus significados em diferentes contextos e sua articulação interdisciplinar, tanto os referentes à Educação Infantil, quanto os do Ensino Fundamental" (PPP, 2002).

Concomitantemente a este objetivo, dever-se-ia os alunos obter conhecimentos teóricos baseados em verdades científicas, principalmente na verificação de problemas de aprendizagem tão presentes no contexto escolar atual.

Este trabalho limita-se a uma amostra específica de uma universidade pública brasileira, não se comparou a outras amostras via grupos controles e/ ou discentes de outras universidades. A análise referida ao longo deste trabaIho procurou sinteticamente averiguar se esta proposição havia sido realizada dentre os alunos do curso de Pedagogia, envolvendo como foco de pesquisa a hiperatividade infantil. Baseado nos resultados pode-se perceber que esta existiu, mesmo que de modo superficial, baseando-se em sua grande maioria nas vivências dos alunos e não nos conteúdos científicos assegurados, que deveria ter sido mais bem explorado e visto com veracidade nas aulas pertinentes ao tema.

Por fim, vale ressaltar que no currículo que se projeta para inicio no ano de 2015 para curso de Pedagogia, foco deste estudo, inclui uma disciplina específica que tratará dos principais temas referentes às dificuldades de aprendizagem, transtornos e outras condições que muitos alunos são atualmente acometidos durante os anos iniciais da Educação Básica.

\section{Referências}

ANDRADE, A. C.;FLORES-MENDOZA, C. Transtorno do Déficit de atenção/Hi- 
peratividade: o que nos informa a investigação dimensional? Estudos de Psicologia, 15(1), Jan-abr/2010, p.17-24.

ARRUDA, M.A. Levados da breca: um guia sobre crianças e adolescentes com o Transtorno do Déficit de Atenção e Hiperatividade (TDAH). Ribeirão Preto: Blanche Ricci, 2008.

BARKLEY, R.A. Transtorno de déficit de atenção/hiperatividade (TDAH): guia completo e autorizado para os pais, professores e profissionais da saúde. Trad. Luis Sergio Roizman. Porto Alegre: Artmed, 2002.

BRASIL. Estatuto da criança e do adolescente. Lei n. 8.069, de 13 de julho de 1990.

BRASIL.Ministério da Educação.Lei de Diretrizes e Base da Educação Nacional. Lei n. 9.394, de 20 de dezembro de 1996.

BRASIL. Ministério da Educação e do Desporto. Secretaria de Educação Fundamental. Referencial Curricular Nacional para a Educação Infantil. Brasília: MEC/SEF, 1998.

BRZOZOWSKI, F. S.; CAPONI, S. Transtorno de Déficit de Atenção com Hiperatividade: classificação e classificados. IXCongreso Internacional De Salud Mental Y Derechos Humanos. 2010.

DuPAUL, G. J.; STONER, G. TDAH nas escolas. Trad. Dayse Batista. São Paulo: M. Books do Brasil, 2007.

ÊIDT, N. M.; TULESKI, S. C. Transtorno de Déficit de Atenção/ Hiperatividade e Psicologia Histórico-Cultural.Cadernos de Pesquisa, v.40, n.139, jan./abr. 2010.

FERREIRA, S. L. Ingresso, Permanência e Competência: uma realidade possível para universitários com Necessidades Educacionais Especiais.2007. Rev. Bras. Ed. Esp., Marília, Jan.Abr. 2007, v.13, n.1, p.43-60.

MATTOS, P. No mundo da lua: Perguntas e respostas sobre transtorno do déficit de atenção com hiperatividade em crianças, adolescentes e adultos. 4 ed. São Paulo: Lemos Editorial, 2005.

MESSINA, L. F.; TIEDEMANN, K. B. Avaliação da memória de trabalho em crianças com transtorno do déficit de atenção e hiperatividade.Psicol. USP v.20 n.2 São Paulo, jun. 2009.

MICHAELIS. Dicionário de Português Online. Ed. Melhoramentos. Disponí- 
vel em: http://michaelis.uol.com.br/moderno/portugues/index.php?lingua=portugues-portugues\&palavra=disrup\%E7\%E3o. Acesso em: 16 fev 2015.

MIRANDA, T. G. et al. O professor e a Educação Inclusiva: Formação, prática e lugares.EDUFBA Salvador, 2012.

OMOTE, S. Estigma no tempo da inclusão.Rev. Bras. Ed. Esp., Marília, Set./ Dez. 2004, v.10, n.3, p.287-308.

PFIFFNER, L.J; BARKLEY, R.A. Rumo à escola com o pé direito: Administrando a educação de seu filho.In: BARKLEY, R.A. Transtorno de déficit de atenção/ hiperatividade (TDAH): guia completo e autorizado para os pais, professores e profissionais da saúde. Trad. Luis Sergio Roizman. Porto Alegre: Artmed, 2002.

RODHE, L.A; BENCZIK, E.B.P. Transtorno de déficit de atenção/hiperatividade: o que é?Como lidar?Porto Alegre: Artes Médicas Sul, 1999.

SANTOS, L. F.; VASCONCELOS, L. A. Transtorno do Déficit de Atenção e Hiperatividade em Crianças: Uma Revisão Interdisciplinar. Psicologia: Teoria e Pesquisa. Out-Dez 2010, Vol. 26 n. 4, pp. 717-724.

SENA, S. S.; SOUZA, L. K. Amizade em meninos com Transtorno de Déficit de Atenção/Hiperatividade.Estud. psicol. (Campinas) vol.30 no. 3. Campinas Jul/Set. 2013.

SIGNOR, R. Transtorno de déficit de atenção/ hiperatividade: uma análise histórica e social.Rev. bras. linguist. apl. Belo Horizonte, Out./ Dez. 2013,vol.13, no.4.

SILVA, J. C. M. Formação continuada dos professores: visando a própria experiência para uma nova perspectiva. Revista Iberoamericana de Educación / Revista Ibero-americana de Educação ISSN: 1681-5653 n.o 55/3-15/04/11. 